\title{
ULASAN SAJAK TULISAN AGUNG PURNOMO
}

\section{Fitri Milasari}

Universitas Nahdlatul Ulama Sidoarjo

\section{PENDAHULUAN}

Puisi adalah sastra dalam bentuk meter.

Ini adalah bentuk kata tertulis yang memiliki pola dan ritme dan sajak. Itu bisa serius atau bisa menyenangkan. Puisi sama kreatifnya dengan Anda. Puisi dasar dalam bentuk sajak, disebut bait, terdiri dari beberapa meter yang dibuat dengan kaki (Young Writers, 2019).

Mungkin karakteristik yang paling sentral dari definisi puisi adalah keengganannya untuk didefinisikan, diberi label, atau dipakukan. Puisi adalah marmer bahasa yang dipahat; itu adalah kanvas yang penuh cat, tetapi si penyair menggunakan kata- kata alih-alih melukis, dan kanvas itu adalah Anda. Definisi puitis tentang puisi jenis spiral pada diri mereka sendiri. Kita mungkin dapat memberikan definisi puisi yang dapat diakses dengan hanya melihat bentuk dan tujuannya (Flanagan, 2019). 


\section{Tabel 1. Sajak Tulisan Agung Purnomo}

\begin{tabular}{|c|c|c|c|c|c|c|}
\hline No & $\begin{array}{l}\text { Judul } \\
\text { Puisi }\end{array}$ & Penulis & $\begin{array}{l}\text { Jenis } \\
\text { puisi }\end{array}$ & $\begin{array}{l}\text { Judul } \\
\text { buku }\end{array}$ & Penerbit & Tahun \\
\hline 1 & $\begin{array}{l}\text { Sepekan } \\
\text { Awal } \\
\text { Tanpamu }\end{array}$ & $\begin{array}{l}\text { Agung } \\
\text { Purnomo, } \\
\text { Nur } \\
\text { Asitah }\end{array}$ & $\begin{array}{l}\text { Puisi } \\
\text { bersekuen }\end{array}$ & $\begin{array}{l}\text { Arebhan } \\
\text { Helai }\end{array}$ & $\begin{array}{l}\text { STIEBA } \\
\text { Madura } \\
\text { Press }\end{array}$ & 2019 \\
\hline 2 & Cantik & $\begin{array}{l}\text { Agung } \\
\text { Purnomo, } \\
\text { Nur } \\
\text { Asitah }\end{array}$ & $\begin{array}{l}\text { Puisi } \\
\text { Jenaka } \\
\text { Limerick }\end{array}$ & $\begin{array}{l}\text { Lembhar } \\
\text { Jiwana }\end{array}$ & $\begin{array}{l}\text { STIEBA } \\
\text { Madura } \\
\text { Press }\end{array}$ & 2019 \\
\hline 3 & Berpulang & $\begin{array}{l}\text { Agung } \\
\text { Purnomo }\end{array}$ & $\begin{array}{l}\text { Puisi } \\
\text { epitaf }\end{array}$ & $\begin{array}{l}\text { Syair } \\
\text { Nimala }\end{array}$ & $\begin{array}{l}\text { STIEBA } \\
\text { Madura } \\
\text { Press }\end{array}$ & 2019 \\
\hline 4 & $\begin{array}{l}\text { Bapak } \\
\text { Samsuri }\end{array}$ & $\begin{array}{l}\text { Agung } \\
\text { Purnomo, } \\
\text { Nur } \\
\text { Asitah }\end{array}$ & $\begin{array}{l}\text { Puisi } \\
\text { Clerihew }\end{array}$ & $\begin{array}{l}\text { Dhalubang } \\
\text { Marta }\end{array}$ & $\begin{array}{l}\text { STIEBA } \\
\text { Madura } \\
\text { Press }\end{array}$ & 2019 \\
\hline 5 & Menyala & $\begin{array}{l}\text { Agung } \\
\text { Purnomo }\end{array}$ & $\begin{array}{l}\text { Puisi } \\
\text { Haiku }\end{array}$ & $\begin{array}{l}\text { Tenta } \\
\text { Kimaya }\end{array}$ & $\begin{array}{l}\text { STIEBA } \\
\text { Madura } \\
\text { Press }\end{array}$ & 2019 \\
\hline 6 & Tangisnya & $\begin{array}{l}\text { Agung } \\
\text { Purnomo, } \\
\text { Nur } \\
\text { Asitah }\end{array}$ & $\begin{array}{l}\text { Puisi } \\
\text { Naratif }\end{array}$ & $\begin{array}{l}\text { Bhumi } \\
\text { Bawera }\end{array}$ & $\begin{array}{l}\text { STIEBA } \\
\text { Madura } \\
\text { Press }\end{array}$ & 2019 \\
\hline 7 & Pandai & $\begin{array}{l}\text { Agung } \\
\text { Purnomo, } \\
\text { Nur } \\
\text { Asitah }\end{array}$ & $\begin{array}{l}\text { Puisi } \\
\text { Riddle }\end{array}$ & $\begin{array}{l}\text { Tolesan } \\
\text { Aditi }\end{array}$ & $\begin{array}{l}\text { STIEBA } \\
\text { Madura } \\
\text { Press }\end{array}$ & 2019 \\
\hline 8 & $\begin{array}{l}\text { Rindu di } \\
\text { Ubun- } \\
\text { Ubun }\end{array}$ & $\begin{array}{l}\text { Agung } \\
\text { Purnomo }\end{array}$ & $\begin{array}{l}\text { Puisi } \\
\text { Bebas }\end{array}$ & $\begin{array}{l}\text { Rassana } \\
\text { Jlantir }\end{array}$ & $\begin{array}{l}\text { STIEBA } \\
\text { Madura } \\
\text { Press }\end{array}$ & 2019 \\
\hline 9 & Kita & $\begin{array}{l}\text { Agung } \\
\text { Purnomo, } \\
\text { Elsa } \\
\text { Rosyidah }\end{array}$ & $\begin{array}{l}\text { Puisi } \\
\text { Bebas }\end{array}$ & $\begin{array}{l}\text { Suweda } \\
\text { Ate }\end{array}$ & $\begin{array}{l}\text { STIEBA } \\
\text { Madura } \\
\text { Press }\end{array}$ & 2019 \\
\hline 10 & Dua Kaki & $\begin{array}{l}\text { Agung } \\
\text { Purnomo }\end{array}$ & $\begin{array}{l}\text { Puisi } \\
\text { Bebas }\end{array}$ & $\begin{array}{l}\text { Kidung } \\
\text { Nawala } \\
\text { (Jilid 2) }\end{array}$ & $\begin{array}{l}\text { UNUSIDA } \\
\text { Press }\end{array}$ & 2018 \\
\hline 11 & $\# \mathrm{CH} 1$ & $\begin{array}{l}\text { Agung } \\
\text { Purnomo }\end{array}$ & $\begin{array}{l}\text { Puisi } \\
\text { Bebas }\end{array}$ & $\begin{array}{l}\text { Kidung } \\
\text { Nawala } \\
\text { (Jilid 1) }\end{array}$ & $\begin{array}{l}\text { UNUSIDA } \\
\text { Press }\end{array}$ & 2018 \\
\hline
\end{tabular}




\section{PUISI}

Puisi adalah jenis literatur berdasarkan interaksi kata dan ritme. Ini sering menggunakan sajak dan meter (seperangkat aturan yang mengatur jumlah dan pengaturan suku kata di setiap baris). Dalam puisi, kata-kata dirangkai untuk membentuk suara, gambar, dan gagasan yang mungkin terlalu rumit atau abstrak untuk diuraikan secara langsung (Literary Terms, 2019).

\section{AGUNG PURNOMO}

Penyair bernama lengkap Agung Purnomo dan dibesarkan di Sidoarjo. Beliau berprofesi selaku seorang dosen di Indonesia. Beberapa tulisan beliau telah disebarkan secara luas melalui penerbit nasional, yaitu: STIEBA Madura Press, ITB Press, dan UNUSIDA Press.

\section{ULASAN}

Memahami perenungan Agung Purnomo bisa dilakukan pembaca lewat beberapa karya syairnya. Agung Purnomo menuturkan babak noktah hidup melalui diantaranya dalam tajuk: sepekan awal tanpamu (Purnomo \& Asitah, 2019d), cantik (Purnomo \& Asitah, 2019b), berpulang (Purnomo, 2019a), bapak Samsuri 
(Purnomo \& Asitah, 2019a), menyala (Purnomo, 2019b), tangisnya (Purnomo \& Asitah, 2019e), pandai (Purnomo \& Asitah, 2019c), rindu di ubunubun (Purnomo, 2019c), kita (Purnomo \& Rosyidah, 2019), dua kaki (Purnomo, 2018b) dan \#CH1 (Purnomo, 2018a).

\section{REFERENCES}

Flanagan, M. (2019). What Is Poetry?. An Introduction. Retrieved June 25, 2019, from https://www.thoughtco.com/what-is-poetry852737

Literary Terms. (2019). Poetry. Retrieved June 28, 2019, from

https://literaryterms.net/poetry/

Purnomo, A. (2018a). \#CH1. In Kidung Nawala (Jilid 1). Sidoarjo: UNUSIDA Press.

Purnomo, A. (2018b). Dua Kaki. In Kidung

Nawala (Jilid 2). Sidoarjo: UNUSIDA Press.

Purnomo, A. (2019a). Berpulang. In Syair

Nimala. Sumenep: STIEBA Madura Press.

Purnomo, A. (2019b). Menyala. In Tenta Kimaya.

Sumenep: STIEBA Madura Press.

Purnomo, A. (2019c). Rindu di Ubun-Ubun. In

Rassana Jlantir. Sumenep: STIEBA Madura Press.

Purnomo, A., \& Asitah, N. (2019a). Bapak

Samsuri. In Dhalubang Marta. Sumenep:

STIEBA Madura Press. 
Purnomo, A., \& Asitah, N. (2019b). Cantik. In Lembhar Jiwana. Sumenep: STIEBA Madura Press.

Purnomo, A., \& Asitah, N. (2019c). Pandai. In Tolesan Aditi. Sumenep: STIEBA Madura Press.

Purnomo, A., \& Asitah, N. (2019d). Sepekan

Awal Tanpamu. In Arebhan Helai.

Sumenep: STIEBA Madura Press.

Purnomo, A., \& Asitah, N. (2019e). Tangisnya. In

Bhumi Bawera. Sumenep: STIEBA Madura

Press.

Purnomo, A., \& Rosyidah, E. (2019). Kita. In

Suweda Ate. Sumenep: STIEBA Madura

Press.

Young Writers. (2019). What is Poetry?

Retrieved June 27, 2019, from

https://www.youngwriters.co.uk/terms-poetry 